\title{
DE OTTO VON BISMARCK A ANGELA MERKEL: DO “PERIGO ALEMÃO” AO "NEONAZISMO" NO BRASIL
}

\author{
From Otto von Bismarck to Angela Merkel: from \\ "German peril" to "neo-Nazism" in Brazil
}

\author{
René E. Gertz
}

\begin{abstract}
RESUMO
A presença de alemães e de seus descendentes no Brasil, desde que o país se tornou independente, no início do século XIX, afetou, em algum grau, as relações com a Alemanha, no mínimo, desde a unificação desta, em 1871. Apesar de eventuais efeitos positivos dessa presença, costumam ser destacadas, com mais ênfase, as consequências negativas, verificadas durante as cerca de sete décadas entre a unificação alemã e a Segunda Guerra Mundial, e que podem ser resumidas na expressão "perigo alemão", isto é, o papel que essa população poderia exercer numa eventual política agressiva da Alemanha em relação ao Brasil. Essa perspectiva perdeu sua plausibilidade após a guerra, mas um novo fantasma ronda a imagem sobre essa população - o "neonazismo". Este artigo constitui uma tentativa para responder se a referida população efetivamente tem algo a ver com esse novo mal.
\end{abstract}

Palavras-chave: neonazismo; imigração alemã; preconceitos étnicos.

\begin{abstract}
The presence of Germans and their descendents in Brazil, since the country became independent, at the beginning of the $19^{\text {th }}$ century, has affected, in a certain degree, the relations with Germany, at least, since the unification in 1871. In spite of casual positive effects of this presence, the negative consequences, observed during about seven decades from German unification to Second World War, are usually more highlighted and can be summarized in the expression "German peril", that means,

" Professor no Departamento de História da Pontifícia Universidade Católica do Rio Grande do Sul; professor aposentado pela Universidade Federal do Rio Grande do Sul, Porto Alegre, Brasil. E-
\end{abstract} -mail: gertz@cpovo.net 
the role which this population could exercise in an eventual German's aggressive politic towards Brazil. This perspective has lost its plausibility after the war, however a new phantom haunts this population's image - "neo-Nazism". This article is an attempt to answer in which sense this population effectively has to do with this new evil, or not.

Keywords: Neo-Nazism; German emigrants; ethnic preconceptions.

\section{Tentativa de explicitação do tema ${ }^{1}$}

Imigrantes e descendentes costumam exercer algum tipo de influência sobre as relações entre os países de sua origem e de seu destino. ${ }^{2}$ No caso da Alemanha e do Brasil, o fato de este ter recebido o segundo maior contingente de imigrantes vindos daquela (ainda que em quantidade muito inferior aos Estados Unidos da América, que foram o destino preferido), as relações políticas, econômicas e culturais transcorreram - no mínimo entre 1871, ano da fundação do império alemão, e 1942, ano do início do segundo enfrentamento bélico entre os dois países -, em parte, sob o pano de fundo da presença de um número significativo de população de origem alemã. De forma generalizada, pode-se afirmar que esse período de cerca de 70 anos da história das relações germano-brasileiras teve como fator, no mínimo, interveniente, com intensidade variável, no decorrer do tempo, a discussão sobre o assim chamado "perigo alemão". Isso significa que a presença das "colônias alemãs" era vista como fator importante na definição dos interesses da Alemanha em relação ao Brasil. Ainda que houvesse

1 Alguns elementos contidos neste texto foram apresentados sob o título "Preconceitos étnicos e movimentos "neonazistas", no I Encuentro de las Ciencias Humanas y Tecnológicas para la Integración en el Conosur, promovido pelo Instituto Federal de Educação, Ciência e Tecnologia Sul-Rio-Grandense, Pelotas, em 6 de maio de 2011. Este texto, no entanto, é uma versão totalmente nova, especificamente redigida para esta revista.

2 Continua vivo o imaginário sobre esse tipo de influenciação. Em janeiro de 2012, o italiano Cesare Battisti, conhecido por prolongada pendenga entre Brasil e Itália, em torno do pedido de sua extradição, visitou o Fórum Social Temático, em Porto Alegre, onde se encontrou com o governador Tarso Genro. Entre as críticas ao governador por essa atitude, uma, do deputado Edson Brum, foi formulada nos seguintes termos: "Temos uma colônia italiana muito forte no Brasil, e não é bom para o estado a relação do governador com um terrorista condenado [na Itália]" (Correio do Povo, Porto Alegre, 25 de janeiro de 2012, p. 4). 
divergências entre os contemporâneos a esse respeito, e ainda que haja divergências entre os estudiosos sobre aquilo que "realmente aconteceu", esse período está relativamente bem investigado pela ciência histórica. ${ }^{3}$

Há, também, estudos sobre as relações do Brasil com a(s) Alemanha(s) nas décadas do pós-guerra. ${ }^{4}$ Em alguns casos, a presença de imigrantes e de seus descendentes continua sendo referida até hoje. ${ }^{5}$ Desconhecem-se, porém, estudos sobre a importância atribuída a eles pelas instâncias formuladoras de políticas oficiais alemãs em relação ao Brasil, e das instâncias brasileiras em sentido inverso. Provavelmente, não existe consenso em nenhum dos dois lados, de forma que essa questão fica na dependência de constelações pessoais, das concepções dos ocupantes dos cargos a quem esse assunto esteve afeto em diferentes momentos deste último período. Mas se o "perigo alemão", no sentido da fase anterior, não é mais verbalizado, porque pouco plausível, há indícios de que ao menos certos formuladores de políticas alemãs em relação ao Brasil preferem agir como se a "colônia alemã" no Brasil não existisse quando pautam suas ações nos campos político, econômico e tecnológico-cultural. Como este texto centrará sua atenção sobre o Rio Grande do Sul, cabe citar como exemplo

3 Em toda esta parte inicial do texto, serão indicadas apenas algumas poucas obras de referência. A quem interessar, pode consultar a bibliografia constante nas próprias obras indicadas, com detalhes sobre temas como a situação político-cultural nas próprias "colônias alemãs" do Brasil, e afins. Em relação ao período 1871-1918, cf., em especial, VOGT, John. Deutschtum and the German peril in Brazil, 18901914. Charlottesville: University of Virginia, 1964; HELL, Jürgen. Die Politik des Deutschen Reiches zur Umwandlung Südbrasiliens in ein überseeisches Neudeutschland (1880-1914). 1966. Tese (Doutorado em História) - Universidade de Rostock, Rostock, 1966; BRUNN, Gerhard. Deutschland und Brasilien. (18891914). Colônia/Alemanha: Böhlau Verlag, 1971; LUEBKE, Frederick C. Germans in Brazil: a comparative history of cultural conflict during World War I. Louisiana: Louisiana State University Press, 1987; BONOW, Stefan Chamorro. A desconfiança sobre as comunidades germânicas de Porto Alegre durante a Primeira Guerra Mundial: cidadãos leais ou retovados? 2011. Tese (Doutorado em História) - PUCRS, Porto Alegre, 2011. Quanto aos anos 1930-1940, cf. SEITENFUS, Ricardo Antônio Silva. O Brasil de Getúlio Vargas e a formação dos blocos: o processo do envolvimento brasileiro na II Guerra Mundial. Rio de Janeiro: Companhia Editora Nacional, 1985; GERTZ, René E. O fascismo no sul do Brasil: nazismo, germanismo, integralismo. Porto Alegre: Mercado Aberto, 1987. Sobre a importância atribuída às "colônias" e aos seus habitantes em relatos de viajantes alemães, de todo esse período, cf. LISBOA, Karen Macknow. Mundo novo, mesmo mundo: viajantes de língua alemã no Brasil (1893-1942). São Paulo: HUCITEC/FAPESP, 2011. p. 250-290.

4 BANDEIRA, Moniz. O milagre alemão e o desenvolvimento do Brasil: as relações da Alemanha com o Brasil e a América Latina (1949-1994). São Paulo: Ensaio, 1994; LOHBAUER, Christian. Brasil - Alemanha: fases de uma parceria (1964-1999). São Paulo: Fundação Konrad Adenauer/EDUSP, 2000 .

5 DUNGEN, Johannes von. Vom Freund zum Partner: die deutsch-brasilianischen Kulturbeziehungen im Wandel. Stuttgart: Institut für Auslandsbeziehungen e. V., 2011. p. 18-20. 
a política adotada pelo Instituto Goethe de Porto Alegre, nos anos 1980 e continuada até hoje, ainda que sem qualquer tipo de "radicalização". ${ }^{6}$

Mas tudo isso ainda está pouco investigado. Um tema sobre o qual existem estudos publicados é a presença de fugitivos do nazismo, com alguns dados sobre sua eventual permanência e atuação no país, após 1945, com possíveis efeitos sobre as relações entre brasileiros e alemães. ${ }^{7}$ Alguns pesquisadores estão tentando investigar, também, os anos posteriores à Segunda Guerra, com vistas a verificar a política brasileira de repatriação de alemães e descendentes que se encontravam na Alemanha e mesmo a admissão de novos imigrantes que nunca tinham vivido no Brasil. Esse tema inclui a possível vinda - legal ou clandestina - de militantes do nazismo. ${ }^{8}$

Existe, porém, um problema que ganhou visibilidade a partir da transição do regime militar para a democracia, no decorrer dos anos 1980, estendendo-se pelos últimos 20 anos. Trata-se de manifestações e de atos classificados como "neonazistas". ${ }^{9}$ E este é o tema deste texto. Por um lado, os estudos relativos à presença nazista no Brasil, nas décadas de 1930/1940,

6 Antes de fazer a referência, cabe destacar que o Instituto Goethe não é um órgão estatal alemão, mas é, sem dúvida, o mais importante instrumento de difusão cultural da Alemanha no exterior. Em 1996, Gerhard Jacob escreveu: "Foi justamente nesse período [do regime militar] que se destacou por sua coragem e isenção Kurt Scharf, diretor do Goethe na primeira metade da década de 1980 [...] A atitude destemida de Scharf lhe valeu, de um lado, a ira de certos círculos reacionários da chamada colônia teutobrasileira de Porto Alegre [...], mas, por outro, a outorga da cidadania honorária de Porto Alegre" (JACOB, Gerhard. O Instituto Cultural Brasileiro-Alemão de Porto Alegre. In: FISCHER, Luís Augusto; GERTZ, René E. (Coords.). Nós, os teuto-gaúchos. Porto Alegre: Editora da Universidade/UFRGS, 1996, p. 153). Isso está longe de significar que, em situações concretas, afinidades "nacionais" não possam exercer algum tipo de influência. E há até instâncias que continuam a destacar a "contribuição alemã para a formação da nação brasileira”, como se pode ver num livro editado pela Câmara de Comércio e Indústria Brasil-Alemanha (A história alemã do Brasil - Die deutsche Geschichte Brasiliens. São Paulo: Câmara Brasil-Alemanha, 2001).

7 Exil in Brasilien: die deutschsprachige Emigration 1933-1945. Frankfurt/M: Die Deutsche Bibliothek, 1994; KESTLER, Izabel Maria Furtado. Exílio e literatura: escritores de fala alemã durante a época do nazismo. São Paulo: EDUSP, 2003; ECKL, Marlen (Ed.). “... auf brasilianischem Boden fand ich eine neue Heimat": autobiographische Texte deutscher Flüchtlinge des Nationalsozialismus 1933-1945. Remscheid: Gardez! Verlag, 2005; ECKL, Marlen. “Das Paradies ist überall verloren”: das Brasilienbild von Flüchtlingen des Nationalsozialismus. Frankfurt am Main/Alemanha: Vervuert Verlag, 2010.

8 Isso sem esquecer que alguns alemães residentes no Brasil nas décadas de 1930/1940 filiados ao partido nazista continuaram residindo aqui, nos anos posteriores. Maria Luiza Tucci Carneiro (USP) desenvolveu um projeto intitulado "Missionários do Reich: a presença de nazistas no Brasil (19321978)"; Méri Frotscher (UNIOESTE) desenvolve projeto sobre "Migrações alemãs para o Brasil após a Segunda Guerra Mundial, sob perspectiva transnacional (1945-1955)".

9 À exceção das citações, a palavra sempre aparecerá entre aspas, para sinalizar que sob essa rubrica costumam ser subsumidas várias coisas diferentes entre si, e, ainda, pelo fato de que, em nenhum momento, se tentará apresentar uma definição do conceito, querendo, com isso, indicar, apenas, que se está tratando daquilo que tanto em fontes acadêmicas quanto no senso comum recebe essa denominação. 
mostram que o partido só admitia, como membros, cidadãos alemães descendentes de alemães com cidadania brasileira estavam excluídos e, mais ainda, brasileiros de outras origens. ${ }^{10}$ Nesse sentido, o nazismo no Brasil foi algo essencialmente "alemão". Por outro lado, ocorreu, porém, que, além da atividade nazista, havia atividade fascista italiana e atividade da Ação Integralista Brasileira (AIB). Independente da intensa discussão sobre as relações entre esses três movimentos, não há dúvida de que, com isso, a atividade que se pode classificar, através de um conceito genérico, de "fascista" no Brasil dos anos 1930 não é exclusivamente alemã nem envolve apenas cidadãos de nacionalidade ou etnia alemã. ${ }^{11}$ Claro, na época, os próprios atores insistiam numa nítida distinção entre "nazismo", "fascismo italiano" e "integralismo", mas a pergunta que se coloca hoje em dia é se o "neonazismo" no Brasil é algo tipicamente "alemão", ou se isso é apenas uma visão do senso comum, derivada, entre outras razões, da própria palavra utilizada para sua denominação e das referências a Hitler. As considerações que seguem constituem uma tentativa de aproximação a essa questão. Por razões que o leitor compreenderá ao longo do texto, a base para a análise é constituída, sobretudo, por dados colhidos no Rio Grande do Sul.

\section{Alguns momentos e fatos}

Notícias sobre supostos ou efetivos atos nazistas no Rio Grande do Sul podem ser encontradas ao longo de todo o período que vai de 1945 a 1990. A descoberta de algum nazista - vivo ou sua ossada - estabelecido

10 MORAES, Luís Edmundo de Souza. Konflikt und Anerkennung: die Ortsgruppen der NSDAP in Blumenau und Rio de Janeiro. Berlim: Metropol, 2005; LUCAS, Taís Campelo. Nazismo d'além mar: conflitos e esquecimento (Rio Grande do Sul, Brasil). 2011. Tese (Doutorado em História) - UFRGS, Porto Alegre, 2011.

11 Sobre as relações entre nazismo e integralismo, cf. GERTZ, O fascismo no sul do Brasil. A tese de doutorado de Ana Maria Dietrich tenta lidar com essa complexidade recorrendo ao conceito de "nazismo tropical" ou "tropicalização do nazismo" (Nazismo tropical? O partido nazista no Brasil. São Paulo: USP, 2007), ainda que, na concepção dela, o centro do enfoque também seja o nazismo. Cabe lembrar que entre os acusados de espionagem no Brasil, durante a Segunda Guerra, não há menção a alemães ou descendentes longamente estabelecidos no sul do país; em contrapartida, são arrolados nomes de brasileiros "típicos" (cf. HILTON, Stanley E. A guerra secreta de Hitler no Brasil. Rio de Janeiro: Nova Fronteira, 1983). 
no país atiçava a memória sobre a presença de militantes na década de 1930 e muitas pessoas passavam a imaginar sua permanência às centenas ou milhares em território gaúcho e brasileiro. E, certamente, aconteceram alguns atos que mereceram essa classificação. Mas é, sobretudo, a partir do final do regime militar e da promulgação da Constituição de 1988 que as referências a esse tema aumentaram na imprensa. E há algumas razões objetivas que ajudam a explicar essa situação, pois ocorreram fatos que podiam ser interpretados como avanço daquilo que agora passou a ser chamado de "neonazismo".

O primeiro fato objetivo é uma maior densidade de ocorrências e/ou uma maior densidade de referências sobre o tema em nível mundial, com a consequente vulgarização do tema também no Brasil (hooligans e coisas do gênero; informações sobre o aumento de grupos xenófobos na Alemanha, após a reunificação do país, etc.). Naquilo que tange à população local de origem alemã (mas também italiana, polonesa e outras), a redemocratização do Brasil e o restabelecimento da tolerância levaram a uma maior visibilidade das "etnias", da qual a difusão das festas típicas se tornou o símbolo mais conhecido. ${ }^{12}$ Durante o governo de Pedro Simon, no Rio Grande do Sul (1987-1990), a Secretaria de Educação estabeleceu que as comunidades locais poderiam participar da definição de quais línguas estrangeiras seriam ensinadas nas escolas públicas estaduais locais, fato que ajudou a intensificar aquilo que se poderia chamar de "re-etnização" de setores da população gaúcha. Isso, certamente, foi identificado por alguns cidadãos como renascimento do nacionalismo alemão em solo brasileiro, algo que, eventualmente, podia ser visto como aparentado com o nazismo, "neonazismo".

Mas a redemocratização, com a garantia das liberdades democráticas, também parece ter incentivado grupos que até então não ousavam manifestar publicamente suas opiniões. Nesse sentido, há a registrar, no mínimo, duas manifestações "neonazistas", de alguma importância numéri-

12 O início desse processo é anterior. Quando, em 1974/1975, o Rio Grande do Sul era governado por um descendente de italianos (Euclides Triches) e o Brasil por um descendente de alemães (Ernesto Geisel), o poder público gaúcho resolveu patrocinar o "biênio da imigração e colonização" (150 anos de imigração alemã, em 1974, e 100 anos de imigração italiana, em 1975). Em relação aos festejos na "colônia alemã", cf. ROEHE, Nara Simone Viegas Rocha. O sesquicentenário da imigração alemã no Rio Grande do Sul em 1974 como corolário das relações econômicas Brasil-Alemanha. 2005. Dissertação (Mestrado em História) - PUCRS, Porto Alegre, 2005. 
ca, no Estado. Uma foi a "Editora Revisão", criada por Siegfried Ellwanger Castan, já em meados da década de 1980, em Porto Alegre, que publicou livros e outros materiais revisionistas sobre o Holocausto, a Segunda Guerra Mundial e também sobre temas contemporâneos. A outra foi o surgimento, no início da década de 1990, do movimento da "República do Pampa", separatista, cujo líder foi Irton Marx, residente em Santa Cruz do Sul, um dos mais típicos municípios de colonização alemã. Nas manifestações desse movimento há elementos classificáveis na mesma categoria. Ambos os movimentos e seus líderes sofreram repressão policial e judiciária, de forma que sua visibilidade foi diminuindo, gradativamente, ao longo dos anos $1990 .^{13}$

Na medida em que a atuação desses dois movimentos foi perdendo espaço na mídia, começaram a multiplicar-se, porém, notícias sobre outros grupos, no início, identificados como skinheads, mas, aos poucos, sendo classificados como "neonazistas", em geral não constituídos na forma de entidades, como os dois recém-citados. Eram, basicamente, manifestações de preconceitos verbais ou através de pichações contra judeus, negros, homossexuais, praticados por jovens entre, aproximadamente, 15 e 30 anos. Essas manifestações, no entanto, em alguns momentos posteriores, degeneraram em atos de agressão física. Para exemplificar, serão citados alguns poucos desses episódios - sem qualquer pretensão de apresentar uma lista completa.

Em 8 de maio de 2005 - simbolicamente, o dia em que se lembravam os 60 anos do final da Segunda Guerra na Europa -, três rapazes com quipá (que os identificava como judeus) foram atacados fisicamente, no bairro Cidade Baixa, em Porto Alegre, por um grupo cujos integrantes já haviam enfrentado problemas com a polícia e com o poder judiciário por causa de episódios em que haviam manifestado preconceito e ódio contra determinados grupos, além de terem pertencido a uma banda cujas músicas faziam apologia do nazismo. No mínimo, um dos rapazes atacados sofreu lesões graves. ${ }^{14}$

13 Referenciações bibliográficas a esses movimentos serão feitas numa seção de análise historiográfica, mais adiante.

$14<$ http://tj-rs.jusbrasil.com.br/noticias/2333356/grupo-envolvido-em-atos-violentos-contra-judeus-devera-responder-diante-do-tribunal-do-juri >. Acesso em: 23/01/2012. Tendo em vista a intensiva utilização de fontes buscadas na internet, cabe destacar que todas as matérias citadas estão guardadas em arquivos do autor, seja na forma impressa, seja na forma eletrônica, incluindo áudios e vídeos. Isso significa que, na hipótese de o leitor não conseguir localizá-las on-line, pode solicitá-las ao autor. 
Outro episódio ocorreu ao final de um GRENAL ${ }^{15}$, em 16 de setembro de 2007, quando torcedores do Grêmio atacaram um rapaz, que ficou seriamente ferido. Segundo informações da imprensa, o ataque foi feito por um grupo "neonazista" infiltrado na torcida gremista. ${ }^{16}$ A partir desse momento, a ação desses grupos e a contra-ação de autoridades policiais passaram a ganhar destaque na imprensa e na opinião pública. Nesse sentido, o jornal Zero Hora, de Porto Alegre, de 29 de junho de 2008, dedicou uma página inteira ao tema, sob o título "PC [Polícia Civil] vai deflagrar ofensiva para deter os neonazistas". ${ }^{17}$ Lembrou-se a história dos grupos "neonazistas" no Rio Grande do Sul, desde o início da década, quando o delegado Paulo Cesar Jardim começou a se dedicar ao assunto - passando a ser visto como a figura central da ação investigadora e repressora a delitos desse tipo. Mais adiante, retornaremos a ele.

Em maio de 2009, ocorreu outro caso de grande repercussão nacional, e até internacional -, no contexto do assassinato de um casal de jovens, no Paraná, episódio que, por enquanto, fica apenas registrado, para também ser retomado em outro item. Finalmente, cabe lembrar uma situação ocorrida em novembro de 2010, quando

a Polícia Civil apreendeu [...] material usado em encontros de grupos no centro da Capital. Livros, CDs, facas e uma soqueira estão entre os materiais apreendidos pela Polícia Civil, em um local usado para encontros de grupos neonazistas em Porto Alegre. Mas entre as apreensões, o que mais impressionou o delegado Paulo Cesar Jardim foi um vídeo em que o grupo White Power Sul Skin (Poder da Raça Branca do Sul, numa tradução livre) faz ameaças ao senador gaúcho Paulo Paim (PT). ${ }^{18}$ "A informação que tínhamos é de que haveria bombas e armas neste endereço e que seriam usadas em um ataque nos próximos dias" - disse o delegado, especialista na investigação de grupos neonazistas no Estado. As armas e os explosivos não foram encontrados. O responsável pelo local também não foi localizado pela polícia. Segundo o delegado, o homem teria

15 Jogo de futebol entre as equipes de Grêmio e Internacional, de Porto Alegre.

$16<$ http://esporte.uol.com.br/futebol/ultimas/2007/10/03/ult59u132368.jhtm>. Acesso em: 18/01/2012; <http://www.battlecentral.xpg.com.br/forum/showthread.php?t=36886>. Acesso em: $18 / 01 / 2012$.

17 Zero Hora, Porto Alegre, 29 de junho de 2008, p. 16.

18 O senador gaúcho Paulo Paim é negro. 
relações com o grupo que, em 2005, esfaqueou três judeus no bairro Cidade Baixa. ${ }^{19}$

Pela importância do personagem (senador), este caso teve muita repercussão e vários desdobramentos. Também em relação a ele serão feitas mais algumas breves referências, em outro lugar.

A enumeração destes poucos casos serve para ilustrar o tema "neonazismo" no Rio Grande do Sul, ao longo da última década.

\section{Alguns estudos sobre "neonazismo"}

Apesar da repercussão na imprensa e em parte da opinião pública, o "neonazismo" no Brasil parece ter sido pouco estudado em trabalhos acadêmicos. Quando se faz uma busca na listagem de teses e dissertações das universidades brasileiras, no portal da Coordenação de Aperfeiçoamento de Pessoal de Nível Superior (CAPES), órgão do Ministério da Educação que cuida do ensino pós-graduado, a palavra "neonazismo" registra apenas oito títulos. Destes, na verdade, metade apenas tangencia o tema, restando quatro que efetivamente se ocupam com ele. ${ }^{20}$ Como o foco deste texto é a relação entre os "alemães" do Brasil ou as "colônias alemãs" - especialmente no sul do país - e o "neonazismo", serão referidos apenas aqueles trabalhos (e alguns poucos mais) que tratam de forma direta sobre esse assunto. ${ }^{21}$

$19<$ http://www.senadorpaim.com.br/verImprensa.php?id=916-senador-e-alvo-de-perseguicao-de-neonazistas $>$. A notícia é de 8 de novembro de 2010; acesso em: 18/01/2012.

$20<$ http://capesdw.capes.gov.br/capesdw/Pesquisa.do;jsessionid=A4E0D4515E977DA39 C545DA89A9E5663 autor $=\&$ tipoPesqAutor $=$ T\&assunto $=$ neonazismo\& tipoPesqAssunto $=$ T\&ies $=\&$ tip oPesqIes=T\&nivel $=$ \&anoBase $=>$. Acesso em: 23/01/2012. Os trabalhos (dissertações de mestrado) que efetivamente tratam do assunto são: CRUZ, Natalia dos Reis. Negando a História. A Editora Revisão e o neonazismo. Niterói: UFF, 1997; ALMEIDA, Alexandre. Skinheads: os mitos ordenadores do poder branco paulista. São Paulo: PUCSP, 2004; JESUS, Carlos Gustavo Nóbrega de. Anti-semitismo e nacionalismo, negacionismo e memória: Revisão Editora e as estratégias da intolerância (1987-2003). Assis: UNESP, 2004; DIAS, Adriana Abreu Magalhães. Os anacronautas do teutonismo virtual: uma etnografia do neonazismo na Internet. Campinas: UNICAMP, 2007.

21 Por essa razão, fica excluída da apreciação a dissertação de Alexandre Almeida sobre os skinheads em São Paulo. Cabe recordar também a tese de doutorado de Márcia Regina da Costa (Os carecas do subúrbio - caminhos de um nomadismo moderno. São Paulo: PUCSP, 1992). 
Na dissertação de Natalia dos Reis Cruz sobre a Editora Revisão e seu fundador, é feita uma clara ligação direta com a "colônia alemã", pois, no caso de seu idealizador, trata-se de um "gaúcho, residente em Porto Alegre e descendente de alemães" (p. 45). O mesmo pressuposto transparece logo no início do trabalho, quando a autora define que

os objetivos deste estudo são dois: primeiro, situar a Editora Revisão em seu contexto histórico-cultural. É importante salientar que o proprietário da editora, Siegfried Ellwanger Castan, é um descendente de alemães, sendo, portanto, necessário incluir a análise da presença de colônias alemãs no sul do Brasil. Este dado traz uma questão crucial: o cultivo do germanismo, ou seja, da cultura alemã, no sul do país. Parto da hipótese de que o germanismo é um componente essencial para explicar tanto a emergência de um fenômeno como a Editora Revisão - sua presença pode ser percebida pela pretensa defesa que Castan faz do "povo alemão" - quanto as alterações a ele aportadas por Castan (p. 3, sem grifos no original).

Para reforçar essa perspectiva, a autora ainda apresenta, mais adiante, um item dedicado ao "germanismo no sul do Brasil" (p. 66-71). ${ }^{22}$ Uma dissertação não arrolada na citada lista da CAPES que trata do separatismo "neonazista" liderado por Irton Marx foi defendida por Caroline Kraus Luvizotto, na UNESP de Marília. ${ }^{23}$ Apesar de o texto apresentar problemas de articulação lógica, destacando a tradição separatista da Revolução Farroupilha e da Revolução Federalista (quando a historiografia desconhece tendências separatistas na última), com ambas não apresentando qualquer relação significativa de causa e efeito naquilo que tange aos "alemães", mas quando a autora chega ao separatismo contemporâneo, estes passam a ser vistos como fundamentais. $\mathrm{O}$ simples fato de a autora destacar que o ponto de partida para o trabalho foi sua monografia de conclusão de curso de graduação intitulada Migração e separatismo: alemães no processo de criação do movimento separatista no sul do Brasil (p. 10), e ainda o fato de que o título, na versão original, foi Etnicidade e separatismo no Rio Grande

22 Os destaques foram acrescentados ao original.

23 LUVIZOTTO, Caroline Kraus. Cultura gaúcha e separatismo no Rio Grande do Sul. São Paulo: Cultura Acadêmica, 2009. 
do Sul, mostram como essa variável é importante para a autora. E ela chega a ser explícita, quando escreve: "considerando que grande parte do Estado do Rio Grande do Sul foi colonizada por alemães e que há notícias de que militantes do Movimento Separatista Sulino contemporâneo demonstram sua simpatia por princípios nazistas, é possível configurar a influência do nazismo-germanismo no movimento" (p. 49, sem grifo no original).

O citado trabalho de Carlos Gustavo Nóbrega de Jesus sobre a Editora Revisão e um trabalho de Newton Duarte Molon sobre o separatismo de Irton Marx não estabelecem relações de causa e efeito entre "alemães" e esses dois movimentos. ${ }^{24}$

Resta a dissertação de Adriana Abreu Magalhães Dias. Trata-se de um estudo sobre "neonazismo" na internet. Mesmo que no texto não se encontrem afirmações lapidares de que os "alemães" seriam os responsáveis pela existência do "neonazismo" no Brasil, encontra-se, na página 35, a afirmação muito clara de que haveria 90.000 "neonazistas" no Brasil, "cerca de metade disso em Santa Catarina" (sem grifo no original). Como existe consenso de que esse Estado é o mais "germânico" do país, é legítimo pressupor que a autora estivesse convicta do papel decisivo dos "alemães" no estabelecimento desse escore. Além disso, em outras partes do texto, a autora destaca a imigração alemã e seus efeitos, como a suposta ou efetiva preservação da identidade étnica, para, na página 109, afirmar que, "como seus antepassados de Santa Catarina e do Rio Grande do Sul, os internautas do neonazismo no Brasil são separatistas".

Se agregarmos às referências contidas na dissertação manifestações da autora na imprensa, reforçam-se as evidências de que, para ela, existe relação clara entre população de origem alemã e "neonazismo". Assim, numa entrevista, informou que muitos participantes de sites "neonazistas" se apresentam como de "sangue alemão" e que "a autogarantia de uma origem europeia, particularmente teutônica, é muito forte, principalmente nos internautas que se identificam como moradores de Santa Catarina”. E, logo adiante, estabelece uma linha de continuidade da situação atual com o nazismo: "um dado importante a ser recordado é que o Estado abrigou o maior núcleo de nazistas no Brasil na década de 1930, seguido de perto pelo

24 JESUS, op. cit. (o texto foi publicado em livro, com o mesmo título, pela Editora da UNESP, São Paulo, em 2006); MOLON, Newton Duarte. O colapso da União: o separatismo no Brasil. São Paulo: Pensieri, 1994. 
Rio Grande do Sul". Essa frase não admite outra interpretação a não ser a de que o "neonazismo" constitui um desdobramento natural do nazismo dos anos 1930/1940. E como o nazismo era um fenômeno ou produto da "colônia alemã", a dedução lógica que se impõe é a de que o "neonazismo" também o é. ${ }^{25}$

\section{A visão do senso comum}

Se autores acadêmicos apresentam uma clara tendência em atribuir o "neonazismo" aos "alemães brasileiros", pode-se imaginar que essa opinião também vigore entre a população em geral ${ }^{26}$ Basta rastrear a internet, para confirmá-lo. ${ }^{27}$ Iniciemos por uma personalidade de grande influência na opinião pública, por sua suposta ou efetiva luta pelos Direitos Humanos, desde a década de 1970, como presidente do Movimento de Justiça e Direitos Humanos de Porto Alegre, Jair Krischke. ${ }^{28}$ Em 2008, foi entrevistado pelo Instituto Humanitas, da UNISINOS, quando lhe foi feita a seguinte pergunta: "O crescimento da violência, como a atuação de grupos neonazistas como os skinheads, estaria ligado à colonização alemã no Rio Grande do Sul?". A resposta de Krischke foi categórica:

O relatório do governo norte-americano a respeito da situação das vítimas no mundo destaca esse episódio. No Rio Grande do Sul, em Santa Catarina e parte do Paraná, temos uma situação bem particular. Trata-se de uma região de forte colonização alemã e que, em termos ideológicos, ficou parada no tempo.

$25<$ http://groups.google.com/group/midiateca-hannah/browse thread/thread/ 9256377704bc4173>. Acesso em: 30/01/2012. Aqui é necessário registrar um pequeno erro factual cometido pela autora - o Estado com o maior número de pessoas filiadas ao partido nazista foi São Paulo.

26 Deve-se destacar que, obviamente, não existem pesquisas sobre os níveis de difusão dessa visão entre a população - trata-se, aqui, exclusivamente, de constatar sua existência.

27 Considerando a plausibilidade de que sejam "coisa de alemão", não vamos citar opiniões sobre a Editora Revisão e o movimento da República do Pampa, restringindo-nos às manifestações classificadas como "neonazistas" ocorridas na última década.

28 Entre muitas homenagens e atos de reconhecimento, nacionais e internacionais, Krischke foi agraciado com a "Comenda Dom Helder Câmara", pelo Senado da República $(<$ http://senadorpedrosimon. blogspot.com/>; acesso em: 27/01/2012). 
Ainda hoje, atuam inspirados na Alemanha nazista e apoiam o projeto de Hitler. ${ }^{29}$

É verdade que a imprensa, em geral, mostra algum comedimento em atribuir, de forma expressa, os episódios classificados como "neonazistas" aos "alemães" gaúchos. Possivelmente, isso se deva a um código de ética jornalística, pois não é de bom tom denunciar atos de preconceito "étnico" e, simultaneamente, apontar um grupo "étnico" por essa maldade. Além disso, existe o dado objetivo de que até maio de 2009 nenhum dos episódios apontados havia ocorrido na "colônia alemã". Talvez seja por isso que vinculações explícitas entre "alemães" e "neonazismo" sejam encontradas com mais facilidade na imprensa estrangeira que na do Rio Grande do Sul. Assim, num site estrangeiro em que se falava do incidente no GRENAL, em setembro de 2007, podia ler-se que "they have to decide if they want to be Argentinians (sic) or Germans", "precisam decidir, se querem ser argentinos (sic) ou alemães". ${ }^{30}$

Mas a situação mudou claramente a partir de abril/maio de 2009, quando aconteceu o rumoroso assassinato de um casal de "neonazistas" por colegas de militância, no Paraná. Um dos envolvidos foi o jovem (na época, 21 anos) Jairo Maciel Fischer, cujos pais, vindos daquele Estado, haviam se estabelecido em Teutônia, no Rio Grande do Sul (um município típico de colonização alemã), para onde ele mesmo também havia se mudado, 18 meses antes do assassinato, depois de ter sido expulso da casa de sua irmã, no Paraná, por causa da militância "neonazista". Após o assassinato, o jovem voltou a Teutônia, onde foi preso, em maio de 2009. Com isso, parecia que a ação "neonazista" havia, finalmente, chegado àquele lugar que sempre se enxergara como seu "berço", a "colônia alemã". E a partir desse momento, ocorreu uma certa normalização na atribuição dessa maldade aos "alemães".

Fiquemos num exemplo. Quando o jornal Zero Hora on-line, de 19 de maio de 2009, publicou uma matéria sob o título "Base de novo grupo neonazista estava sendo montada no Vale do Taquari e na Serra", foi postada

$29<$ http://www.ihuonline.unisinos.br/index.php?option=com_content\&view $=$ article \&id=1 $658 \&$ secao $=252>$. Acesso em: 29/11/10.

$30<\mathrm{http}: / /$ www.bigsoccer.com/forum/showthread.php?t=607386>. Acesso em: 27/01/2012. Cabe lembrar que o Grêmio Foot-Ball Porto-Alegrense foi fundado, basicamente, por alemães e descendentes, em 1903. Nenhum dos dois rapazes presos como responsáveis pela citada agressão possui sobrenome total ou parcialmente alemão, mas sim sobrenomes "autenticamente" brasileiros. 
uma enxurrada de comentários na página. Algumas delas dão uma ideia das opiniões presentes na opinião pública sobre o papel dos "alemães" nesse novo episódio "neonazista". "O problema é que o povo de lá pensa que é alemão. Nasceram no Brasil e se dizem alemães. Tenho parentes no Vale do Taquari, e até hoje não encontrei nenhum brasileiro por lá, são todos alemães" (Luli, Porto Alegre). "Por que não pegam numa enxada e vão capinar por aí? Pensam que são alemães, não passam de caboclos, assim como nós. Bando de babacas" (Flávio, Porto Alegre). "Perfeito Luli... nasceram no Brasil, falam português (o alemão que falam não existe, é apenas uma piada), e acham que são alemães! Acordem para a realidade!" (Pedro Ernesto, Porto Alegre). "Em muitas regiões de imigração do RS impera um sentimento de que os descendentes de italianos e alemães são europeus de fato: e por muitas vezes têm uma postura bastante racista! Inclusive circulam comentários do tipo: 'a cidade tá ficando ruim porque tá vindo muito brasileiro morar aqui'! Talvez crianças que cresçam numa sociedade assim acabem por se tornarem esses idiotas neonazistas. Gostaria que todos esses brasileiros pseudoeuropeus pudessem ir pra Europa para serem feitos de chacota" (Rafael, Santa Maria). ${ }^{31}$

Como o grupo que assassinara o casal no Paraná, suposta ou efetivamente, tinha um projeto de criação de um novo país no sul do Brasil (New Land ou Neuland) e como um dos acusados do assassinato foi preso em Teutônia, uma típica "colônia alemã", criou-se um enorme alvoroço, não só no Rio Grande do Sul, mas no Brasil inteiro. ${ }^{32}$ A deputada gaúcha Maria do Rosário Nunes - a quem se atribui a afirmação de que "quando estou com raiva digo coisas que depois esqueço" 33 - apressou-se a criar uma comissão externa da Câmara dos Deputados (CEXNEONA) para investigar a ofensiva "neonazista" sobre o Brasil, que teria seu foco de irradiação no Rio Grande do Sul (ainda que na reunião do Paraná na qual ocorreu o assassinato do casal houvesse pessoas de vários estados brasileiros, sendo Jairo Maciel

$31<$ http://zerohora.clicrbs.com.br/zerohora/jsp/default.jsp?uf=1\&local=1\&section=Geral\& newsID=a2515630.xm>. Acesso em: 20/5/2009 - aparentemente, esse site não está mais acessível para não assinantes.

32 A revista $I s t o E$, com data de 20 de maio de 2009, apresentou extensa matéria, de 6 páginas, denotando a repercussão nacional. Essa matéria, por sua vez, teve repercussão internacional (<http://brasilien. mediaquell.com/2009/08/27/die-gefahr-der-neuen-neonazis-in-brasilien-8399/>; acesso em: 22/01/2012).

33 <http://www.deolhoseouvidos.com.br/edi\%E7\%F5es/edi\%E7\%E3o_08_2007.htm>. Acesso em: 19/01/2012. 
Fischer - paranaense de origem - o único que, naquele momento, residia no Rio Grande do Sul). ${ }^{34}$

Uma olhada para além-fronteiras, mais uma vez, nos dá uma ideia clara daquilo que se passava na cabeça de uma parte da opinião pública. Num site estrangeiro, com matéria originária do Rio de Janeiro, podia ler-se que "last month, Brazilian police thwarted a plan by a neo-Nazi group called New Land to bomb two synagogues in the city of Porto Alegre. In addition, a large amount of neo-Nazi materials have been seized mainly in the Southern states, which are known to have a large concentration of Brazilians of both German and Arab descent" (sem grifo no original). ${ }^{35}$

Apesar da agitação em torno do caso, os relatos da imprensa baseados nos comunicados policiais não conseguiram apresentar, em relação a Teutônia, qualquer outro fato além da prisão do citado Jairo Maciel Fischer. Mas as suspeitas em relação ao conjunto da população local tiveram novo round, um ano e três meses depois, em agosto de 2010, quando paradas de ônibus, ao longo da rodovia que atravessa o município, apareceram pichadas com símbolos nazistas e dizeres racistas. Até hoje, não houve um esclarecimento público sobre aquilo que realmente aconteceu (há indícios de que tenha sido um ato de provocação), mas a imprensa, de imediato, abriu enormes manchetes sobre o "retorno" do "neonazismo" ao município. Poucos dias depois, tanto o delegado de polícia local, Mauro José Barcellos Mallmann, quanto o delegado Paulo Cesar Jardim, dado como maior conhecedor e monitorador dos "neonazistas" gaúchos, declararam, publicamente, que não houvera atos "neonazistas". Jardim foi categórico:

$34<$ http://www.camara.gov.br/proposicoesWeb/fichadetramitacao?idProposicao=440613>. Acesso em: 30/01/2012).

$35<$ http://www.thephora.net/forum/archive/index.php/t-51022.html >; <http:/jta.org/news/ $\operatorname{article} / 2009 / 06 / 07 / 1005697 /$ brazil-sets-anti-neo-nazi-commission>. Acesso em: 22/01/2012. ["No mês passado, a polícia brasileira frustrou o plano de um grupo neonazista chamado New Land em cometer um atentado à bomba contra duas sinagogas, na cidade de Porto Alegre. Além disso, grande quantidade de material neonazista foi apreendida, em especial nos estados do sul, que são conhecidos por possuírem uma grande concentração de brasileiros de descendência alemã e árabe"]. É interessante notar que a "conexão árabe-germânica" que transparece nessa referência foi retomada, mais recentemente, por ocasião da inauguração do Museu do Holocausto, em Curitiba (20/11/2011), pelo deputado gaúcho Pedro Westphalen, ao afirmar que "os grupos neonazistas gaúchos não são expressivos, mas se diz preocupado com a situação na Tríplice Fronteira e a possibilidade de ação no país de extremistas ligados ao Irã" ( $<$ http://www.conib. org.br/noticia-completa.asp?id=991>; acesso em: 20/01/2012). Até o delegado Jardim fez menção a essa variável: "Ao concluir, o delegado dr. Jardim também falou sobre a presença do Hezbollah e do Hamas em Foz de Iguaçu e no Chuí” (<http://www.pletz.com/blog/bnai-brith-recebe-delegado-especialista-em-neonazismo/>; acesso em: 18/01/2012). 
"Eu afirmo que não existe grupo nazista em Teutônia". E justificou sua posição: "Eu tenho excelentes informantes na região, e esse tipo de crime, com certeza, não existe lá". A suspeita de que se tratou de um atentado, de uma provocação contra os teutonienses, deriva do fato de que Jardim classificou os acontecimentos como "invenção". ${ }^{36}$

Porém, a profundidade com que se impregnara em parte da opinião pública a conviç̧ão de uma estreita ligação entre as características da população local e o "neonazismo" pode ser ilustrada por dois exemplos. No texto redacional do Correio do Povo que segue ao desmentido do delegado Jardim, lê-se que Teutônia é um "município com 25 mil habitantes e origem alemã", lembrando que, em 2009, ali "um jovem foi detido e cinco pessoas respondem processo em liberdade" - como a indicar que o redator não acreditava muito no desmentido do delegado. (Os grifos da citação são meus.) $)^{37}$

Mas há ainda um exemplo mais impressionante ligado a esta suposta segunda onda de "neonazismo" em Teutônia. Cerca de duas semanas após o desmentido da ocorrência de atos "neonazistas", por parte dos dois citados delegados de polícia, a imprensa de Lajeado - município próximo a Teutônia - noticiou que o procurador da República local, Nilo Marcelo de Almeida Camargo (cuja jurisdição abrange este município), resolveu instaurar um "processo administrativo para análise de possíveis neonazistas na região". Além de a decisão do procurador evidenciar desconfiança em relação às conclusões dos dois delegados, impressiona ainda mais o fato de que a notícia diz que, para a realização da investigação do MPF, se recorrerá a uma antropóloga (!). Isso mostra que a desconfiança em relação aos dois delegados não se restringe ao campo técnico, a aspectos de investigação criminológica, pois para isso a lógica recomenda que se recorresse a peritos criminais. A opção por uma antropóloga indica claramente que o procurador

36 Correio do Povo, Porto Alegre, 26 de agosto de 2010, p. 25.

37 A última parte da frase contém, inclusive, uma inverdade, pois as cinco pessoas que respondem a processo em liberdade não têm absolutamente nada a ver com Teutônia nem com o Rio Grande do Sul. Trata-se de uma evidência da falta de domínio de conteúdo, pois essas pessoas estiveram envolvidas no assassinato do casal no Paraná, sendo provenientes de diversos lugares do Brasil.

$38<$ http://www.independente.com.br/player.php?cod=7773>. Acesso em: 22/01/2012. O procurador da República tomara posse em 4 de julho de 2008, quando, provavelmente, veio residir na região; o delegado Jardim, naquele momento, lidava com o "neonazismo" havia cerca de 10 anos; e o delegado Mallmann atuava há cerca de 12 anos no município de Teutônia. De fato, o ato foi formalizado, conforme prova documento público posterior (<http://1ccr.pgr.mpf.gov.br/atuacao-no-mpf/portarias/41>; acesso em: 21/01/2012). 
da República não só desconfiou de erros dos delegados na investigação dos detalhes do suposto ou efetivo "retorno" de atos "neonazistas" em Teutônia - ele, aparentemente, trabalha com a hipótese de que o conjunto da população do município constitui um "ninho da serpente" em potencial, que merece uma investigação antropológica profunda. E se é assim, a única explicação é a de que pressupõe uma relação natural, óbvia, entre a origem alemã dessa população e o "neonazismo".

\section{A metamorfose do delegado Paulo Cesar Jardim}

Em texto anterior sobre o tema, foi feita uma avaliação crítica dos citados trabalhos acadêmicos sobre "neonazismo" de Natalia Cruz, Caroline Luvizotto e Adriana Dias. ${ }^{39}$ Ali, ficou claro que mesmo nos textos das duas primeiras $^{40}$ as hipóteses iniciais de que a Editora Revisão e o separatismo são "coisa de alemão" - no sentido de que os consumidores da primeira e os apoiadores do segundo fossem, sobretudo, "alemães" - perdem-se, no final, sem qualquer comprovação empírica. O caso de Adriana Abreu Magalhães Dias é ainda mais sintomático, tendo em vista sua reação destemperada quando foram apontadas falhas em suas afirmações..$^{41}$ Em relação a esta última autora, cabe uma observação adicional, para caracterizar sua impressionante metamorfose, no mínimo, referente a um aspecto do tema. Se na dissertação e em várias manifestações da época (2007) afirmou, de forma reiterada, que havia 90.000 "neonazistas" no Brasil, e que metade deles (45.000!) estava em Santa Catarina, dado que, no mínimo, sugeria que uma parcela enorme deles era constituída de "alemães", já não arriscou mais

39 GERTZ, René E. Preconceitos étnicos e movimentos "neonazistas". Texto apresentado no I Encuentro de las Ciencias Humanas y Tecnológicas para la Integración en el Conosur, promovido pelo Instituto Federal de Educação, Ciência e Tecnologia Sul-Rio-Grandense, Pelotas, em 6 de maio de 2011 (ainda não estava publicado por ocasião da redação deste artigo).

40 CRUZ, op. cit.; LUVIZOTTO, op. cit.

41 Uma crítica anterior ao trabalho de Adriana Dias pode ser vista em GERTZ, René E. Os "súditos alemães" no Brasil e a pátria-mãe Alemanha. Espaço Plural, Marechal Cândido Rondon: UNIOESTE, ano IX, n. 19, p. 67-73, 2009 (aqui p. 72-73). Disponível em: <http://e-revista.unioeste.br/index. php/espacoplural/article/view/1929/1524>. Acesso em: 28/01/2012. A transcrição da reação destemperada pode ser vista no texto do autor intitulado "Considerações e estudos em torno de nazismo e 'neonazismo' no Brasil" (p. 47-63), publicado no site <http://www.renegertz.com>. 
palpitar a respeito de números na citada matéria da revista $I s t o E$, de 20 de maio de 2009, levando os autores da matéria a dar seu próprio palpite - 350 (!), em todo o Brasil (p. 88). Mas a metamorfose da antropóloga - sob esse aspecto - não cessou ali. Mais recentemente, foi publicada a informação de que, "de acordo com Adriana [Abreu Magalhães Dias], os neonazistas brasileiros 'baixam' [na internet] muito mais traduções em português, espanhol e inglês, mas dificilmente em alemão. "A grande maioria nem sequer lê em inglês". ${ }^{42}$ Soa curioso que os enormes bandos de "alemães" "germanistas" que, supostamente, constituem a massa do "neonazismo" no Brasil se sirvam de línguas tão bárbaras quanto português, espanhol e, eventualmente, inglês para navegar na internet - desprezando sua gloriosa "língua-mãe"!43

Mas, metamorfoses em relação ao tema "alemães brasileiros" versus "neonazismo" não acontecem apenas no mundo acadêmico, também ocorrem no senso comum, ainda que ali a direção possa ser invertida - da negação inicial de qualquer ligação em direção à defesa de uma clara relação de causalidade. Esse processo será mostrado à mão da trajetória do delegado de polícia gaúcho Paulo Cesar Jardim.

$\mathrm{O}$ autor deste artigo procurou o delegado Jardim, em 12 de maio de 2008, para uma conversa informal sobre "neonazismo". O atendimento foi extremamente cordial e informativo. Do conteúdo da conversa, interessa aqui apenas a afirmação categórica de que ele não teria nada a ver com a "colônia alemã". Mesmo que essa afirmação pudesse causar alguma surpresa, já que Jardim começara a investigar "neonazistas” e a monitorá-los por sugestão - e posterior acompanhamento constante - de Jair Krischke, ${ }^{44} \mathrm{o}$ qual, há muitos anos, afirma haver uma ligação causal direta entre "alemães brasileiros" e "neonazismo", há indícios de que ela tenha sido sincera.

$42<$ http://www.brasildefato.com.br/content/neonazistas-brasileiros-saem-da-toca $>$. Acesso em: 22/01/2012.

43 A inexistência de uma relação direta entre "germanismo" e integralismo (e mesmo nazismo) na década de 1930 foi mostrada há muito tempo (GERTZ, O fascismo no sul do Brasil). Mas o principal conselheiro do delegado Paulo Cesar Jardim em relação a "neonazismo", Jair Krischke, insiste que este deriva do fato de que, em meio aos morros, uns 70 quilômetros ao norte de Porto Alegre, há comunidades em que (ainda) se costuma falar em alemão (<http://www.asa.org.br/boletim/96/96_h1.htm>; acesso em: 04/01/2012). Essas pessoas nunca ouviram a palavra "neonazismo" e, muito menos, sabem de que se trata. $\mathrm{Na}$ verdade, os "neonazistas", quando possuem sobrenome alemão, pertencem à classe média urbana, totalmente "assimilada", e só conseguem dizer "Mein Kampf" depois de muito treino.

44 Como o próprio delegado afirmou em sua fala no Senado da República, em 19 de novembro de 2010, à qual se fará referência a seguir. 
Assim, quando a imprensa e a opinião pública estavam no auge de sua excitação com a prisão de Jairo Maciel Fischer - e a consequente satanização do povo de Teutônia -, e apenas quatro dias antes de a deputada Maria do Rosário Nunes desembarcar em Porto Alegre, com sua CEXNEONA, para "acompanhar as investigações a respeito da quadrilha ${ }^{45}$ de neonazistas desarticulada no Estado do Rio do Grande do Sul" ${ }^{46}$, o delegado fez a seguinte declaração pública:

$\mathrm{Na}$ realidade o que houve em relação à Serra foi um grande exagero - e não foi da minha parte! Na realidade, nós tivemos foi um menino do Alto Taquari [Teutônia] que estava envolvido num crime acontecido lá no Paraná. É claro que nós temos segmentos em todo o Rio Grande do Sul, é claro que nós temos algumas pessoas que simpatizam com esse movimento, e agem em razão dele, mas a base não está na Serra, não, a base está em Porto Alegre, na Grande Porto Alegre. Por isso, eu digo com a maior tranquilidade que a situação não é tão contundente, tão séria quanto pareceu. ${ }^{47}$

Pouco mais de um ano depois dessa declaração, quando novamente se desenhava o fantasma do "retorno" do "neonazismo" a Teutônia, Jardim mais uma vez fez a citada declaração categórica de que isso não era verdade e que tudo fora uma "invenção".

Mas não muito depois disso, a situação mudou. A partir de novembro de 2010, ocorreu uma série de declarações em que o delegado estabelece uma relação entre a origem alemã da população gaúcha, de um lado, e não só a sobrevivência, mas até a origem desse mal em todo o território brasileiro,

45 Como, do ponto de vista técnico-jurídico, uma "quadrilha" pressupõe a associação de "mais de três" pessoas, a deputada Maria do Rosário Nunes pode ter imaginado que, por ser "meio-alemão", Jairo Maciel Fischer valeria, no mínimo, por quatro. No momento em que se escreve este texto (fevereiro de 2012), a deputada é titular da Secretaria dos Direitos Humanos da Presidência da República, onde sua função é a de cuidar dos Direitos Humanos universais de todos os cidadãos brasileiros.

$46<$ http://www.camara.gov.br/proposicoesWeb/fichadetramitacao?idProposicao=440613>. Acesso em: 28/01/2012.

47 http://www.leouve.com.br/geral/serra/regiao/ver/regiao_polacia_civil_diz_que_serra_ nao_tem_grupos_de-38195.html>. Acesso em: 29/01/2012. A citação foi transcrita a partir do áudio que se encontra no site, reproduzindo, portanto, de forma fiel as palavras do delegado. 
de outro. ${ }^{48}$ A primeira manifestação pública importante em que se nota essa guinada aconteceu no Senado da República, em 19 de novembro desse ano, quando, após as supostas ou efetivas citadas ameaças a Paulo Paim, ali foi realizada uma sessão de apoio ao senador e de repúdio ao "neonazismo". Numa fala que inclui referências esotéricas sobre o nazismo em geral, Jardim lembrou a existência do partido nazista no Brasil da década de 1930, acrescentando: "vejam os senhores que tudo isso está acontecendo no Rio Grande do Sul. A origem de tudo isso é no Rio Grande do Sul". Estabeleceu, portanto, uma linha direta de continuidade entre os nazistas alemães daquele tempo com os "neonazistas" atuais. ${ }^{49}$

Mas se na fala diante do Senado as acusações contra a população imigrantista ainda não foram completamente explícitas, isso aconteceu, de forma clara, em uma entrevista ao portal de notícias Terra, publicada em 11 de abril de 2011, cujo título foi "Os neonazistas são bem mais que meia dúzia": "A senhora lembra o seguinte: o sul do Brasil é basicamente originário de colonização alemã, italiana, polonesa". ${ }^{50}$ Finalmente, em 9 de agosto de 2011, através do mesmo portal Terra, voltou a fazer uma declaração dramática: "a origem do povo gaúcho é colonial e, além disso, a Argentina, que abrigou oficiais nazistas após a $2^{\text {a }}$ Guerra Mundial, está aqui do lado e preocupa. Para a consolidação dessa ideologia, deve existir um meio viável, caso do Rio Grande do Sul. O neonazismo é uma coisa que jamais vai acabar" (sem grifos no original). ${ }^{51}$

Não é fácil explicar essa mudança de atitude do delegado Jardim. Pode-se formular apenas algumas hipóteses abstratas. $1^{a}$ ) Pelo fato de ter sido levado por Jair Krischke ${ }^{52}$ a se interessar pelo "neonazismo", poderia

48 O delegado faz uma generalização, que inclui "italianos" e "poloneses". Por absoluta falta de espaço, não será possível fazer uma avaliação das eventuais razões para a inclusão destes dois grupos, sobretudo dos "poloneses" - que foram vítimas de muitas acusações no decorrer da história de sua presença em território gaúcho, mas sobre quem se desconheciam, até agora, referências à prática de maldades nessa direção (cf. GRITTI, Isabel Rosa. Imigração e colonização polonesa no Rio Grande do Sul: a emergência do preconceito. Porto Alegre: Martins Livreiro Editor, 2004).

49 <http://www.senado.gov.br/atividade/plenario/sessao/disc/getTexto.asp?s=203.4.53.O\& $\operatorname{disc}=6 / 1 / \mathrm{S}>$. Acesso em: 21/01/2012.

$50<$ http://terramagazine.terra.com.br/interna/0,,OI5070131-EI6594,00-Os+neonazistas+s ao+bem + mais + que + meia + duzia + afirma + delegado.html $>$. Acesso em: 21/01/2012 - os destaques foram acrescentados ao original.

$51<$ http://noticias.terra.com.br/brasil/noticias/0,,OI5286557-EI5030,00-O+neonazismo+nu nca + acabara+diz+delegado+que+indiciou+no+RS.html $>$. Acesso em: 21/01/2012.

52 Cujo posicionamento pela culpa dos "alemães" sempre foi claro. 
imaginar-se que sempre esteve convicto de que os "alemães" gaúchos são responsáveis por esse mal, mas que ocultava essa sua conviç̧ão por razões táticas. $2^{\mathrm{a}}$ ) Ao menos uma fonte afirma que Jardim teria recebido carta branca de Tarso Genro para acabar com o "neonazismo"53 - como a eleição deste a governador do Rio Grande do Sul coincide com o momento da citada guinada, poderia pensar-se que essa é uma diretriz do próprio governo estadual, a que o servidor público se submeteu, sem contestação, passando a defender uma opinião diferente daquela que vinha defendendo pessoalmente, até então. ${ }^{54}$

Mas há, ainda, uma terceira hipótese, mais racional. A guinada também coincide, cronologicamente, com o episódio no qual teriam sido descobertas ameaças ao senador Paim, por parte de "neonazistas". Poderia imaginar-se que nas buscas então realizadas tivessem sido encontrados fatos novos a respeito da participação dos "alemães". De fato, em entrevista sobre o episódio, o próprio delegado fez referência a essa influência "alemã", pois pôde ler-se que "devido às colonizações italiana, alemã e polonesa, os três Estados do Sul lideram na incidência de grupos ligados à política de Adolf Hitler". ${ }^{55}$ Isso sugere que o delegado fez essa afirmação durante a entrevista. ${ }^{56}$

No entanto, também essa hipótese possui um senão: a ameaça ao senador, aparentemente, foi algo relativo, pois se trataria de um vídeo confeccionado em 2005 (portanto, cinco anos antes de sua apreensão!), no qual apareceriam negros agredindo brancos, além de imagens de Paim. Mas em nenhum momento, tanto no texto redacional quanto nas palavras de viva-voz do delegado, foi feita qualquer referência à apreensão de algum material extraordinário. ${ }^{57}$ Mais uma vez, só resta uma quarta alternativa hipotética muito abstrata: o delegado revelou que a busca foi feita na R. Riachuelo, em

$53<$ http://flitparalisante.wordpress.com/2011/08/16/claudio-julio-tognolli-os-policiaisfederais-de-todo-o-brasil-ainda-nao-sabem-qual-o-rosto-que-a-presidente-dilma-quer-dar-a-sua-pf-corruptaviolenta-empresarial-republicana-ou-customizada-a/>. Acesso: em 28/01/2012.

54 Hipótese puramente abstrata, diante do fato de que o governador é casado com Sandra Krebs, a qual tem dito em público que é "de origem alemã".

55 <http://www.radioguaiba.com.br/Noticias/?Noticia=218489>. Acesso em: 28/01/2012.

56 A notícia circulou em 5 de novembro de 2010.

57 O próprio jornal Zero Hora, que sempre deu o maior destaque possível a qualquer ação classificada como "neonazista", desta vez manchetou que "teria" sido encontrado material com ameaças ao senador Paulo Paim, como a indicar que aquilo que realmente foi apresentado não permitia utilizar o verbo numa versão mais afirmativa (<http://zerohora.clicrbs.com.br/rs/geral/noticia/2010/11/video-encontradocom-grupo-neonazista-teria-ameacas-a-paulo-paim-diz-delegado-3099562.html >; acesso em: 31/01/2012). 
Porto Alegre, mas insistiu que não poderia revelar se foi em uma residência ou em outro lugar. Esse mistério sugere que foi encontrado algo como uma "sede neonazista" e, por isso, o acionamento da imaginação pode levar-nos, mais uma vez, a uma hipótese abstrata: Jardim poderia ter descoberto que esse espaço foi (ou é) financiado por um consórcio de cidadãos representativos da "colônia alemã" do Rio Grande do Sul.

Pela dificuldade de acesso a outras fontes, esse mistério continua. Mas nas informações publicadas não há evidências inequívocas de ameaças concretas ao senador Paim ${ }^{58} \mathrm{e}$, muito menos, da vinculação dessa suposta ou efetiva ameaça com a "colônia alemã". Em outubro de 2011, o autor deste texto teve uma conversa com um jornalista do portal de notícias Terra, o qual acabou publicando uma matéria em que afirma que, ao relatar ao delegado Jardim as reservas daquele que assina este artigo em relação a sua guinada na direção de culpar os "alemães" gaúchos pele "neonazismo", teria dito: "não quero contestá-lo [o professor René Gertz]. O meu conhecimento é oriundo dos próprios documentos apreendidos com eles (neonazistas) e de depoimentos deles prestados na delegacia" ${ }^{59}$ Ficamos na mesma!

\section{Onde estão os "alemães"?}

Diante do mistério reinante em torno da culpa dos "alemães" gaúchos pelo surgimento e pela permanência do "neonazismo" no Brasil, cabe fazer algumas poucas observações finais - absolutamente provisórias.

- Várias afirmações - incluindo repetidas vezes do delegado Jardim - apontam para o fato de que os atos "neonazistas" da última década não foram registrados em regiões de colonização alemã (à exceção do controvertido caso de Teutônia), mas, sim, na capital e na região metropolitana, com mais algumas referências a Caxias do Sul. Ambos esses espaços constituem as maiores aglomerações urbanas do Estado.

58 O que, obviamente, não quer dizer que sua imagem constasse no vídeo pelo apreço que os "neonazistas" lhe tributam.

$59<$ http://noticias.terra.com.br/brasil/noticias/0,,OI5425574-EI5030,00-Historiador+ligar+ neonazismo+a+imigracao+alema+e+irresponsavel.html>. Acesso em: 28/01/2012. 
- O delegado Jardim havia afirmado, em diversas oportunidades, que, ao longo dos últimos dez anos, fichou entre 35 e 40 "neonazistas". Na citada entrevista de agosto de 2011, ao portal Terra, cravou um número exato: 35 . Mesmo que todos tivessem sobrenomes alemães, os estatísticos, certamente, teriam restrições em deduzir conclusões sobre o comportamento dos "alemães", a partir desse número, dentro de um universo de 10 milhões de habitantes do Rio Grande do Sul, dos quais certamente mais de 2 milhões possuem um sobrenome integral ou parcialmente alemão.

- Não está divulgada a lista dos 35 "neonazistas" fichados pelo delegado, mas investigações em diversas fontes permitiram chegar aos sobrenomes de 32 deles. Entre eles, há uma pessoa com apenas um sobrenome (Fábio Roberto Sturm) e mais quatro pessoas com sobrenomes duplos, dos quais um é alemão. Nos sobrenomes - todos duplos - dos 27 restantes não aparece qualquer indício de descendência alemã.

- O jovem que é considerado líder do "neonazismo" no Rio Grande do Sul, no mínimo desde 2005 (nascido em 1985), não possui sobrenome alemão, seu pai fez seu curso de graduação neste Estado, o mestrado no Rio de Janeiro e o doutorado em Portugal; a mãe concluiu sua graduação, seu mestrado e seu doutorado no Rio de Janeiro, fez estágio de pós-doutorado em Portugal; uma filha casou com um português; e no currículo Lattes de ambos estão registrados contatos ou comparecimentos a eventos científicos em vários países - mas nenhum deles na Alemanha.

- O "neonazismo" e sua repercussão, durante a última década, aconteceram num contexto de frequentes manifestações de difamação da população de origem alemã. ${ }^{60}$ Entre muitos exemplos possíveis - que vão do senso mais comum ao senso acadêmico de pessoas com altíssimos títulos de pós-graduação -, sejam citados apenas dois vídeos que circulam na internet. Um reproduz uma matéria do programa "Domingo Espetacular", da TV Record, irradiado em 12 de outubro de 2008, sobre uma suposta "fazenda nazista" no interior de São Paulo. O responsável pela fazenda e pelos atos narrados ${ }^{61}$ foi, porém, um brasileiro "quatrocentão", venerador do nazismo, mas não há qualquer indício de que um único alemão ou "alemão

60 A palavra "difamação" aqui é utilizada no sentido objetivo de que se trata de manifestações com conotação negativa (referente ao passado ou ao presente) que envolvem essa população e que constituem inverdades explícitas, e até falsificações evidentes.

61 Entre outras maldades, ali teriam sido escravizados órfãos negros. 
brasileiro" tivesse estado envolvido nesse episódio. O outro é um vídeo sob o título "Brasil, o próximo alvo", o qual afirma que a Argentina, durante a Segunda Guerra Mundial, desenvolveu um plano para invadir o Brasil e, para tal, contaria com o apoio de Hitler e da população de origem alemã do sul do Brasil. Numa fala de Hitler em que está se referindo à juventude alemã, aparece uma legenda falsificada, segundo a qual ele estaria dizendo "meus compatriotas, criaremos no Brasil uma Nova Alemanha", "transformaremos o Brasil num Estado germânico" - além disso, o vídeo contém outras inverdades claras. ${ }^{62}$

- Por tudo isso, os "alemães" continuam sendo encarados como um problema. Naturalmente, não se sabe que percentual da população brasileira os enxerga dessa forma. Mas também não se sabe quantos os enxergavam sob essa perspectiva nos períodos anteriores à Primeira e à Segunda Guerras Mundiais, mas foram suficientes para levar aos acontecimentos ocorridos naqueles dois momentos (ataques pessoais e depredações de propriedades). O que certamente mudou é que, hoje, poucos culparão o governo alemão por isso. Nesse sentido há, antes, indícios de que alguns membros deste sentem-se constrangidos com as reiteradas notícias sobre "neonazismo" no Brasil. ${ }^{63}$

Recebido em agosto de 2012. Aprovado em março de 2013.

$62<$ http://holocausto-doc.blogspot.com/2008/10/fazenda-nazista-no-brasil-e-o-emprego. html >. Acesso em: 29/01/2012. Tanto o moderador deste programa (Paulo Henrique Amorim) quanto o jornalista que produziu a matéria (Roberto Cabrini) - contando com o auxilio de doutores em História - são bastante conhecidos na televisão brasileira e, certamente, gozam de grande credibilidade junto à opinião pública; <http://www.youtube.com/watch?v=e-Fhs-s7K2g $>$. Acesso em: 29/01/2012. A partir de determinado momento, este segundo vídeo, enquanto exibe as legendas, passou a mostrar uma faixa em vermelho na qual está escrito "legenda ilustrativa", como a indicar que os autores ficaram sabendo das críticas de falsificação que lhes foram feitas e tentaram disfarçá-la. Como se sabe, a única fonte conhecida que afirmava que Hitler teria manifestado intenções geoestratégicas em relação à América Latina foi o livro O que Hitler me disse, de Hermann Rauschning (Rio de Janeiro: Edições Dois Mundos, 1940), que foi denunciado como uma fraude por Wolfgang Hänel, em 1983. Historiadores contemporâneos especializados em Hitler - como Ian Kershaw - afirmam que esse subcontinente nunca fez parte das conjecturas estratégicas do ditador (cf. $<$ http://terramagazine.terra.com.br/interna/0,,OI3757079-EI6782,00-O+mito+Hitler+parte+III.html >; acesso em: 01/02/2012). Vale repetir a informação de que o autor deste artigo guarda todos os arquivos das fontes citadas (para o caso de saírem do ar).

63 "O cônsul geral da Alemanha em SP, dr. Heinz Peter Behr, afirmou que o governo alemão está solidário com a comunidade judaica e demais comunidades perseguidas e à disposição para ajudar" (<http://www.pletz.com/blog/bnai-brith-recebe-delegado-especialista-em-neonazismo/>; acesso em: $18 / 01 / 2012)$. 